\title{
Open Reduction with or without DEGA Osteotomy in Children with DDH before the Age of Two years
}

\author{
M.O.Hegazi, M.A.Mashhour, A.S.Elgazzar and M.A.Zahran \\ Orthopedic Dept., Faculty of Medicine, Benha Univ., Benha, Egypt \\ E-Mail: mohamed.abdelbaky@fmed.bu.edu.eg
}

\begin{abstract}
Formative Dysplasia of the hip is a typical hip condition that effects around 1-3\% of recently conceived kids. In addition, it is the principle reason representing around $29 \%$ of essential hip replace $\neg$ ments up to the sixties old enough. The administration of formative dysplasia of the hip principally attempts to early analyze, to begin the treatment. Concentric decrease of the hip, and sufficient inclusion of the acetabular rooftop are the determinants of treatment whether the hip is set up, subluxated, or profoundly disjoined. Open decrease alone may give industrious decrease to quite a long while; nonetheless, the absence of sufficient bony rooftop over the femoral head would cause biomechanical issues in adulthood. Conversely, Dega osteotomy gives much better inclusion and the endproduct would be more anatomical, which may keep the youngster from growing further joint issues later on. This investigation was completed at Benha University Hospital on two gatherings as follows: Group A: 10 patients went through open decrease with DEGA, Group B: 10 patients went through open decrease without DEGA. Mean age of the investigation populace was 21 months in bunch A, 19 months in bunch B. The influenced side was correct side $(50.0 \%)$ while left side was $50.0 \%$. The IHDI middle of the two gatherings was grade 1 in bunch, some time it was grade 3 in bunch B. At a half year, acetabular record was essentially higher in bunch B (49) contrasted with bunch A (38). P esteem was <0.001. There was no critical distinction between the two gatherings pre-operatively. Concerning, Dislocation was fundamentally higher in bunch B (50.0\%) contrasted with bunch A (0.0). P esteem was 0.033 .
\end{abstract}

Keywords: DDH, Open reduction + DEGA osteotomy, Open reduction without DEGA osteotomy.

\section{Introduction}

Developmental dysplasia of the hip is a run of the mill hip condition that impacts around 1-3\% of as of late considered children. Furthermore, it is the principal clarification speaking to around $29 \%$ of fundamental hip replacements up to the sixties mature enough [1].

DDH is seen as a scope of pathology, that goes from smooth acetabular dysplasia with a consistent hip up to more genuine structures, which are connected with hip instability, with variable degrees of subluxation or even complete detachment [2].

The screening programs sufficiency to early recognize DDH are comprehensively factor as shown by their manager, and suggestive guidelines. Conceded examination achieves essentially more eccentric treatment and extended challenges and disillusionment, so early end and genuine organization are fundamental [3].

The organization of developmental dysplasia of the hip basically endeavors to early examine in order to start the treatment. Acetabular modifying is accepted to be the most extraordinary at the underlying two years of life. After this age, attractive headway can't for the most part be ensured by nonemployable treatment following shut decline [4].

A complete goal in any of these is to give a consistent, amicable, and helpful joint, preferably with normalized life frameworks [5,6].

One of the standard treatment techniques for developmental dysplasia of the hip before the walking age is closed reduction followed by immobilization in a hip Spica cast [7].
In case of shut decline failure to keep up lessened joint or the need of a ridiculous hip circumstance to keep up the diminishing, for instance, over the top internal hip turn despite extended hip grabbing to take care of reduction, this is a message showing that shut strategy isn't sensible for this patient and closed abatement should be avoided to thwart the complexities [8].

The two central complexities of developmental dysplasia of the hip (DDH) treatment are Avascular defilement (AVN) and staying hip dysplasia. Though early lessening of the hip may decrease the pace of outstanding dysplasia, it may fabricate the pace of AVN if there ought to emerge an event of crazy hip joint position [9].

Concentric decline of the hip and acceptable incorporation of the acetabular housetop are the determinants of treatment whether the hip is set up, subluxated, or significantly separated.

Open decline alone may give persevering reduction to a long time; regardless, the nonappearance of adequate hard housetop over the femoral head would cause biomechanical issues in adulthood. On the other hand, Dega osteotomy gives much better consideration and the final result would be more anatomical, which may shield the adolescent from developing further joint issues later on [10].

\section{Patients and methods}

A case series randomized clinical study was done including twenty patients with DDH (ten cases managed by open reduction only - ten cases managed by open reduction and DEGA osteotomy) from 
December 2018 till December 2019 in orthopedic department, Benha university hospital. Patients were divided into two groups.

- Group I: Underwent posterior malleolus fixation with or without syndesmotic screw.

- Group II: Underwent conservative treatment with Syndesmotic screw.

\section{Inclusion criteria}

- Patients with idiopathic hip dislocation.

- less than two years in age.

- medically fit.

\section{Exclusion criteria}

- Patients who refused to join the study after explaining risks and benefits.

- Patients with hip dislocation other than DDH.

- Patients with DDH older than two years of age.

- Patients with DDH who had a previous surgical intervention .

- Patients who are medically unfit

\section{Preoperative evaluation}

Full history taking, complete clinical examination and Radiological evaluation; all patient were examined radiologically by Antero-posterior, Lateral radiographs.

\section{Operative intervention}

1-The procedures were carried out under general anesthesia.

2- Approach anterolateral approach.

3- Open Reduction of the femoral head to the true acetabulum.

4- Femoral de-rotation osteotomy.

\section{5- DEGA osteotomy in group A.}

\section{Post-operative evaluation}

All patients were followed up for at least 6 months

1- X-ray at each follow-up, patients were assessed with AP, lateral.

2- C.T. at the post-operative day one, and after 6 weeks.

\section{Assessment of complications}

Intraoperative, early post-operative and complication during the period of follow up recorded.

\subsection{Statistical methods}

Data management and statistical analysis were done using SPSS vs.25. (IBM, Armonk, New York, United states). Numerical data was summarized as means and standard deviations or medians and ranges. Categorical data was summarized as numbers and percentages.

Comparisons between both groups were done using Mann Whitney $U$ test for numerical data. Categorical data was compared using Chi-square or Fisher's exact test.

All $\mathrm{P}$ values were two sided. $\mathrm{P}$ values less than 0.05 were considered significant.

\section{Results}

Mean age of the study population was 39 years with standard deviation of 9 years. $60.0 \%$ of the study population were males while only $40.0 \%$ were females. Smoking, diabetes and hypertension represented $20.0 \%, 10.0 \%$ and $10.0 \%$ respectively. The most frequent side was right side $(60.0 \%)$ while left side was $40.0 \%$. table 1

Table (1) General characteristics in both groups.

\begin{tabular}{|c|c|c|c|c|c|}
\hline & & & $\begin{array}{c}\text { Group A } \\
(\mathbf{n}=\mathbf{1 0})\end{array}$ & $\begin{array}{c}\begin{array}{c}\text { Group B } \\
(\mathbf{n}=\mathbf{1 0})\end{array} \\
\end{array}$ & $P$ value \\
\hline Age (months) & Mean \pm SD & & $21 \pm 3$ & $19 \pm 3$ & 0.123 \\
\hline Gender & $\begin{array}{c}\text { Males } \\
\text { Females }\end{array}$ & $\begin{array}{l}\text { n }(\%) \\
\text { n }(\%)\end{array}$ & $\begin{array}{c}0(0.0) \\
10(100.0)\end{array}$ & $\begin{array}{l}2(20.0) \\
8(80.0)\end{array}$ & 0.474 \\
\hline Side & $\begin{array}{c}\text { Left } \\
\text { Right }\end{array}$ & $\begin{array}{l}\mathrm{n}(\%) \\
\mathrm{n}(\%)\end{array}$ & $\begin{array}{l}7(70.0) \\
3(30.0)\end{array}$ & $\begin{array}{l}3(30.0) \\
7(70.0)\end{array}$ & 0.074 \\
\hline
\end{tabular}

There were no significant differences between both groups as regard age and gender. $\mathrm{P}$ value were 0.123 and 0.474 .
There was no significant difference between both groups as regard site affected. $\mathrm{P}$ value was 0.074 .

Table (2) IHDI grade in both groups at different time points.

\begin{tabular}{llccc}
\hline & & $\begin{array}{c}\text { Group A } \\
(\mathbf{n}=\mathbf{1 0})\end{array}$ & $\begin{array}{c}\text { Group B } \\
(\mathbf{n = 1 0})\end{array}$ & P value \\
\hline Pre-operative & Median (range) & $4(3-4)$ & $4(3-4)$ & 0.342 \\
Post-operative & Median (range) & $1(1-1)$ & $1(1-2)$ & 0.146 \\
3 months & Median (range) & $1(1-1)$ & $1(1-2)$ & 0.146 \\
6 months & Median (range) & $1(1-1)$ & $3(1-4)$ & 0.023 \\
\hline
\end{tabular}


- At 6 months, IHDI grade was significantly higher in group B (3) compared to group A (1). P value was 0.023 .
- There were no significant differences between both groups as regard IHDI grade at pre-operative time, immediate post-operative and 3 months. $\mathrm{P}$ values were $0.342,0.146$ and 0.146 .

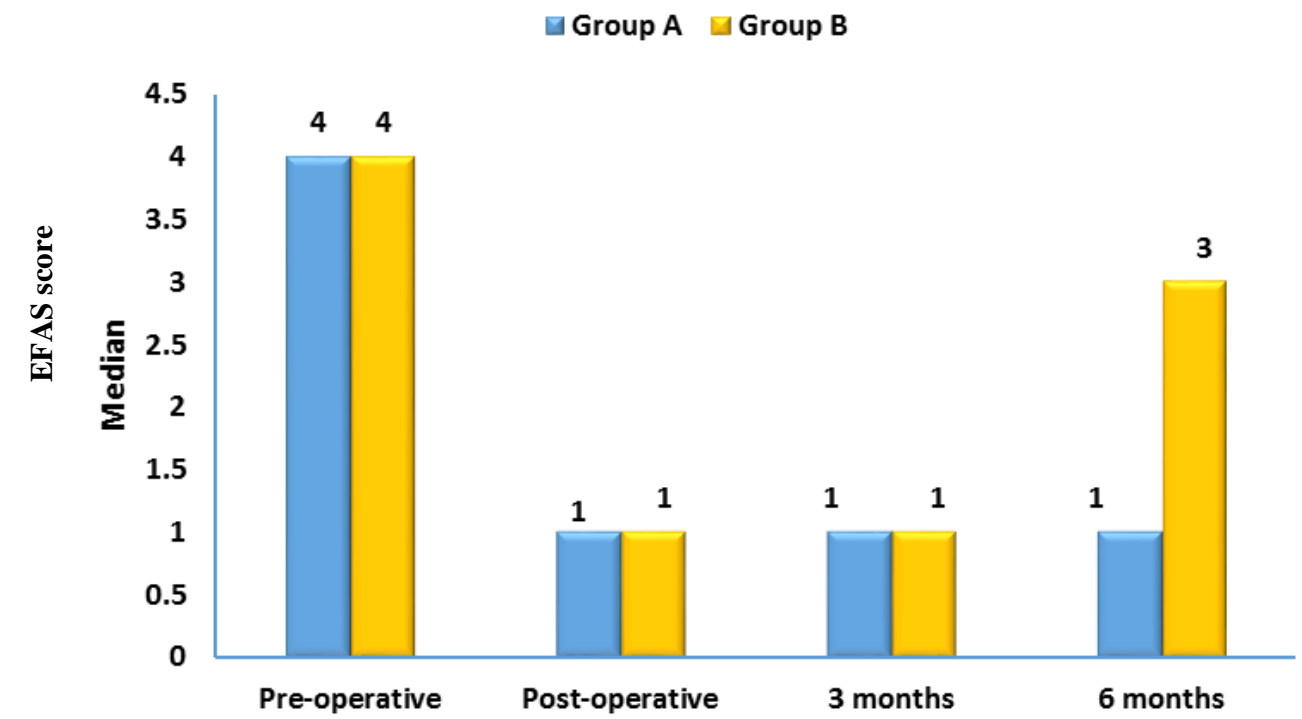

Fig (1) IHDI grade median in both groups.

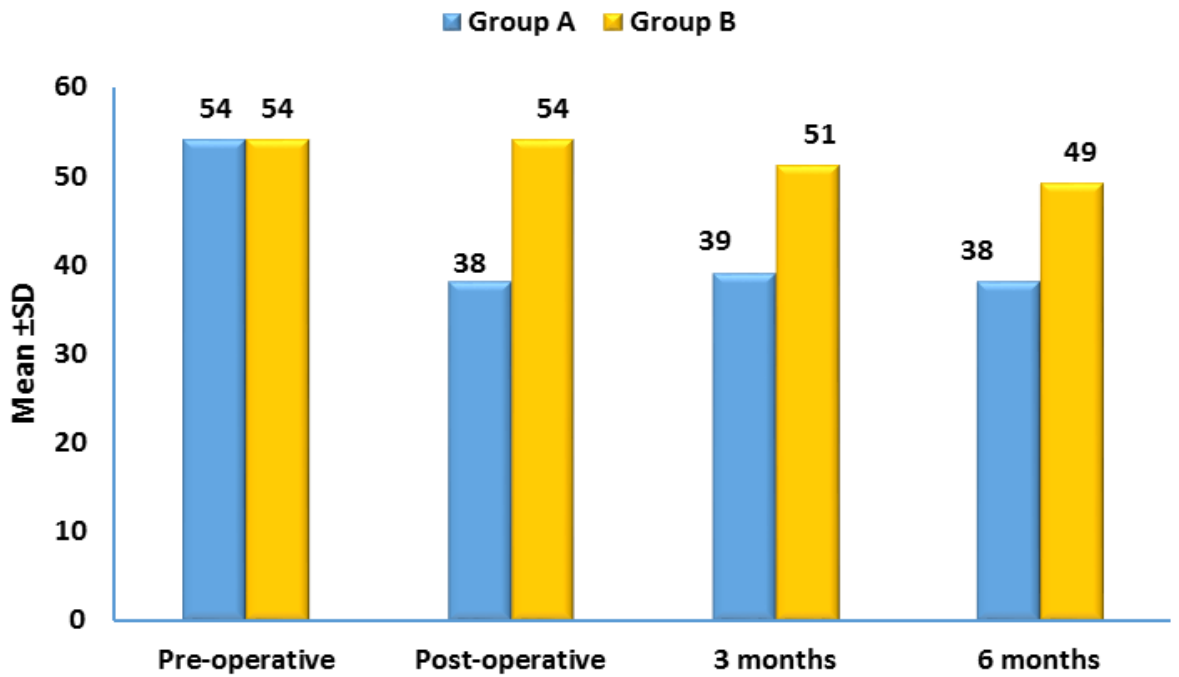

Fig (2) Acetabular Index Mean in both groups.

- Acetabular index was significantly higher in group B (54) compared to group A (38) immediate post-operative. P value was $<0.001$

- At 3 months, acetabular index was significantly higher in group B (51) compared to group A (39). $P$ value was $<0.001$

- At 6 months, acetabular index was significantly higher in group B (49) compared to group A (38). $P$ value was $<0.001$
- There was no significant difference between both groups pre-operatively.

- Dislocation was significantly higher in group B (50.0\%) compared to group A (0.0). P value was 0.033 . 


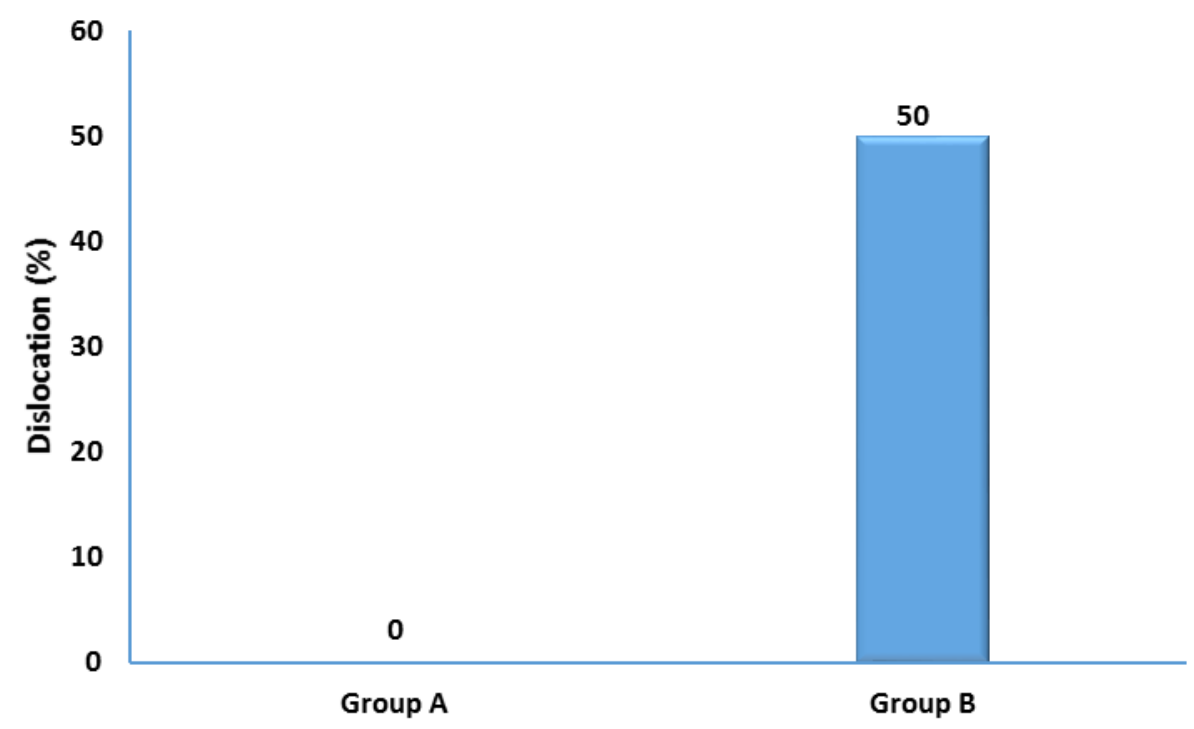

Fig (3) Post-operative dislocation.

Table (3) Complications in both groups.

\begin{tabular}{lcccc}
\hline Complications & & $\begin{array}{c}\text { Group A } \\
(\mathbf{n}=\mathbf{1 0})\end{array}$ & $\begin{array}{c}\text { Group B } \\
(\mathbf{n = 1 0 )}\end{array}$ & P value \\
\hline Dislocation & $\mathrm{n}(\%)$ & $0(0.0)$ & $5(50.0)$ & 0.033 \\
AVN & $\mathrm{n}(\%)$ & $0(0.0)$ & $0(0.0)$ & NA \\
\hline
\end{tabular}

\section{Discussion}

Developmental dysplasia of the hip is a normal hip condition that impacts around $1-3 \%$ of as of late considered children. Likewise, it is the standard explanation speaking to around $29 \%$ of fundamental hip replacements up to the sixties mature enough [1].

DDH is seen as a scope of pathology, that goes from smooth acetabular dysplasia with a consistent hip up to more outrageous structures, which are connected with hip uncertainty, with variable degrees of subluxation or even complete partition [2].

The screening programs practicality to early recognize DDH are comprehensively factor as shown by their director, and suggestive measures. Conceded end achieves generously more perplexing treatment and extended disarrays and disillusionment, so early assurance and authentic organization are central [3].

The organization of developmental dysplasia of the hip dominatingly endeavors to early examine to start the treatment. Acetabular upgrading is accepted to be the best at the underlying two years of life. After this age, pleasing headway can't for the most part be ensured by non-usable treatment following shut lessening [4].

An authoritative target in any of these is to give a consistent, viable, and utilitarian joint, in a perfect world with normalized life frameworks $[5,6]$.

One of the standard treatment techniques for developmental dysplasia of the hip before the walking age is closed reduction followed by immobilization in a hip Spica cast [7].

In case of shut reduction failure to keep up lessened joint or the need of an uncommon hip circumstance to keep up the abatement, for instance, extreme inside hip upheaval despite extended hip hijacking to care for decline, this is a message demonstrating that shut methodology isn't sensible for this patient and closed diminishing should be avoided to prevent the ensnarements [8].

The two key complexities of developmental dysplasia of the hip (DDH) treatment are Avascular decay (AVN) and extra hip dysplasia. But early abatement of the hip may reduce the recurrence of waiting dysplasia, it may extend the event of AVN in case of unprecedented hip joint position [9].

Lessening of the hip and acceptable consideration of the acetabular housetop are the determinants of treatment whether the hip is set up, subluxated, or uncommonly withdrew.

\section{Conclusion}

Open abatement alone may give consistent reduction to a serious drawn-out period of time; regardless, the nonappearance of adequate hard housetop over the femoral head would cause biomechanical issues in adulthood. On the other hand, Dega osteotomy gives much better consideration and the final result would be more anatomical, which may shield the child from developing further joint issues later on [10]. 


\section{References}

[1] O. Furnes, S.A. Lie, B. Espehaug, Hip disease and the prognosis of total hip replacements. J Bone Joint Surg Br, Vol.83,pp.579-86,2001.

[2] M.Sewell, K.Rosendahl, DM.Eastwood, Developmental dysplasia of the hip. BMJ, Vol.339,pp.1242-1248,2009.

[3] S.A. Shipman, M .Helfand, V.A. Moyer, Screening for developmental dysplasia of the hip: a systematic literature review for the US Preventive Services Task Force. Pediatrics, Vol.117,pp.557-76,2006.

[4] R.B. Salter, J.P.Dubos ,The first fifteen years' personal experience with innominate osteotomy in the treatment of congenital dislocation and subluxation of the hip. Clin Orthop Relat Res, Vol.98,PP.72-103,1974.

[5] F.D. Lalonde, S.L. Frick, D.R. Wenger, Surgical correction of residual hip dysplasia in two pediatric age groups. J Bone Joint Surg Am, Vol.84,PP.1148-1156,2002.

[6] M.G. Vitale, D.L. Skaggs, Developmental dysplasia of the hip from six months to four years of age. J Am Acad Orthop Surg, Vol.9,PP.401-411,2001.

[7] M. Cemalettin, Closed reduction in the treatment of developmental dysplasia of the hip Acta Orthop Traumatol Turc, Vol.41 (1) ,pp.2530,2007.
[8] M.C. Aksoy, G. Ozkoc, A. Alanay, Treatment of developmental dysplasia of the hip before walking: results of closed reduction and immobilization in hip Spica cast. Turk J Pediatr, Vol.44,pp.122-7,2002.

[9] M. Belen, M.P. Nicholas, Acetabuloplasties at Open Reduction Prevent Acetabular Dysplasia in Intentionally Delayed Developmental Dysplasia of the Hip: A Case-control Study. Clin Orthop Relat Res, Vol.1999,pp.4501-9,2015.

[10] A.Issın, A.Öner, N.Koçkara, Comparison of open reduction alone and open reduction plus Dega osteotomy in developmental dysplasia of the hip. Journal of Pediatric Orthopedics B, Vol.25,pp.1-6,2016.

[11]C.Chen, T.Wang, K.N.Kuo, Developmental Diseases of the Hip Diagnosis and Management. Intech, Vol.5(3),pp.20-24, 2017.

[12] S.Yilar, S.Toy, M Kose, Comparison of Open Reduction Alone and Open Reduction Plus Pemberton Osteotomy Techniques in the Treatment of Developmental Hip Dysplasia at Walking Age. Eurasian J Med, Vol.51(3) ,PP.228-231,2019.

[13] A. Kothari, G. Grammatopoulos, S. Hopewell, T.Theologis, How does bony surgery affect results of anterior open reduction in walking-age children with developmental hip dysplasia? Clin Orthop Relat Res, Vol.474,PP.1199-208,2016. 